\title{
SEM and AES Analysis of Corrosion in Steel Cans of Meat and Poultry Food Industry Influenced by Microorganisms Affecting the Competitiveness in Northwest of Mexico
}

\author{
César Sánchez Ocampo, ${ }^{1}$ Gustavo López Badilla, ${ }^{1}$ Elizabeth Romero Samaniego, ${ }^{2}$ \\ Sandra Luz Toledo Perea, ${ }^{2}$ and Josefina Campos García ${ }^{2}$ \\ ${ }^{1}$ Ingeniería en Tecnologías de Manufactura, Universidad Politécnica de Baja California, Mexicali, BC, Mexico \\ ${ }^{2}$ Ingeniería Industrial, Instituto Tecnológico de Ensenada (ITE), Ensenada, BC, Mexico \\ Correspondence should be addressed to Gustavo López Badilla; glopezbadilla@yahoo.com
}

Received 24 July 2015; Revised 1 September 2015; Accepted 14 September 2015

Academic Editor: Jisheng Pan

Copyright (C) 2015 César Sánchez Ocampo et al. This is an open access article distributed under the Creative Commons Attribution License, which permits unrestricted use, distribution, and reproduction in any medium, provided the original work is properly cited.

\begin{abstract}
The food industry of meat and poultry food is very important activity in the economy of the northwest of Mexico where the Sonora state (with Hermosillo and Santa Ana cities as arid and semiarid zones and Guaymas as marine regions) and Baja California state (Mexicali as arid zone and Tijuana as marine region) are located. The meat and poultry industries produce meat, milk, and eggs, which are recommended for their nutritive properties. An evaluation of micro- and nanocorrosion was made with an optical sensor used to detect microorganisms (MO) inside of the steel cans. The techniques applied to evaluate the deterioration were the Scanning Electron Microscopy (SEM) and the Auger Electron Spectroscopy (AES), to obtain the morphology of microorganisms formed in the internal area of the metallic containers. Also the chemical composition to identify and determine the conditions for growth of microorganisms was obtained with respect to moisture and temperature in each region analyzed. The sulfur was the principal pollutant agent in arid and semiarid zones and chloride in marine zones that promoted the corrosion process. The presence of corrosion in the food industry decreases their competitiveness.
\end{abstract}

\section{Introduction}

In the States of Sonora and Baja California that are located in the northwest of Mexico, there are more than 50 industrial plants which manufacture food. This type of food industry produces meat and milk of the meat food industry and meat and eggs of the poultry food industry, which are important in the nutritive properties to good health [1]. The managers of these industries plan every day with efficient productive yielding the manufacturing to this region and other states of Mexico where products are sold. These industries are important factors in the economy where they are located, generating a lot of sources of work. To conserve the food of meat and poultry, steel cans are to be used with specialized steel to avoid the formation of MO. This has a negative effect in the competitiveness of this industry with economic losses. But the presence of microorganisms occurred even with specialized steel, in these types of industries that show the study elaborated. Sometimes, the production decrease appears by the presence of microorganisms in the steel cans used to conserve the meat and poultry food [2]. This process can be originated by the presence of air pollutants principally as sulfur in arid and semiarid regions and chlorides in marine zones, penetrating to inside of the industrial plants. The presence of the chemical agents mentioned generates aggressive environments inside of these companies, and with this the indoor atmospheres deteriorate. The air pollutants mentioned above exceed the air quality standards proposed by the environmental authorities of Mexico and United States (US) [3]. The presence of the chemical agents mentioned above and added to the variations in the ranges of relative humidity $(\mathrm{RH})$ and temperature levels higher than $75 \%$ and $35^{\circ} \mathrm{C}$ generates the microbiological corrosion (MBC), and that deteriorates the meat and poultry food. The drastic variations of the climate factors (relative 


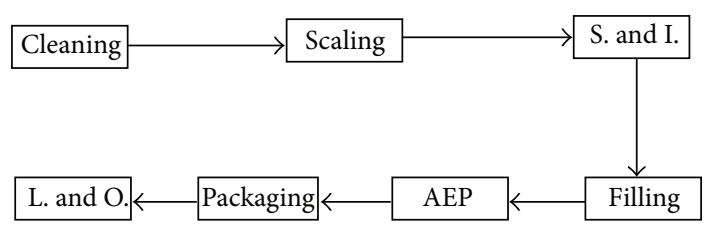

FIGURE 1: Manufacturing steps of SC used in meat and poultry food in the food industries.

humidity and temperature) cause the acceleration of the $\mathrm{MBC}$ and originate visible or nonvisible thin films by the condensation phenomena $[4,5]$. This effect generates the electrochemical process and reduces the productive yielding of industrial equipment and machinery, by the steel cans (SC) used for food preservation. The steel cans are damaged by the atmospheric corrosion and the development of $\mathrm{MO}$ and are sent to garbage, originating economic losses. An analysis at micro- and nanoscale to detect the kinetic mechanism of the chemical reactions of the MBC process with an electronic-optical device was made. The sulfur, chlorides, and other air pollutants as nitrogen oxides and carbon compounds of traffic vehicle and industries were detected in the evaluation at nanoscale [6]. To analyze the generation of MO in the metallic surfaces of the SC, the Scanning Electron Microscopy (SEM) and the Auger Electron Spectroscopy (AES) techniques were used $[7,8]$. The SEM and AES are utilized to detect the principal chemical agents that reacted with the metallic and internal area of the steel cans formed of specialized steel, using the depth profile process in nanometers to determine the thickness of the layers formed.

1.1. Manufacturing Process in Food Industries. The steps of fabrication in the industrial plants of meat and poultry food are specific processes to take care of the hygiene and avoid the generation of MO [9]. The principal steps are described below and are showed in Figure 1.

(a) Cleaning. It represents the process, where the steel cans are washed, cleaned, and dried, to avoid the presence of humidity.

(b) Scalding. The steel cans are disinfected in an immersion area in a tank with hot water.

(c) Sterilization and Inspection. The steel cans are sterilized and inspected, by specialized persons and optical devices.

(d) Filling. It indicates the process of filling the steel cans with meat and poultry food and the operations to close it.

(e) Air Extraction Process. It represents the step where the air creates a vacuum area in the steel cans to avoid the generation of MO.

(f) Packaging. After the steel cans are filled with food, they are packaged to be sold.

(g) Labeling and Ordering. The food products are labeled to determine the type of food products and they are organized in sections to be distributed.
1.2. The Food Industry and the Competitiveness. The competitiveness of industry as Porter mentions depends on the strategic choice and the ability of industry to innovate and improve [10]. In another sense, competitiveness is controllable, as the competitiveness of companies, where it also depends on developing their skills available and where to direct their resources. This is where the premise of competitiveness strategic management plays a very important role for the organization [11]. The analysis of competitiveness is an important economy of industrial operations that is much discussed in the literature of recent times and based on different approaches to analyze subject. It is a dynamic term that should be understood in a systematic way. The industrial plants are increasingly preparing for the manufacture of its products but sometimes are not ready when additional costs are presented. This causes a decrease in the levels of productivity and economics, also reducing the reliability of the manufactured products and competitiveness. Some industries reduce their number of employees or in a drastic situation may close.

1.3. Atmospheric Corrosion. One of the major causes of generation of MO in the inner sections of the metal containers of beef and chicken that occurred inside of the food industry is the climate variations and the presence of air pollutants mentioned above, in each region, causing deterioration of both foodstuffs. There are specialized techniques and conservation methods used, to maintain good food and thus maintain food safety [12]. But the processes of this type of industries are not exempted by the presence of atmospheric corrosion principally the presence of $\mathrm{MBC}$ and the development of $\mathrm{MO}$ by the excess of levels of air pollutants as sulfur and chlorides inside of these types of companies. These microorganisms deteriorate meat and poultry products by the development of colonies of MO, causing bad symptoms of health and stomach diseases in humans. The presence of fast and slow generation of MBC inside of meat and poultry food industries in each city varied, according to the climatic and pollution factors and the specialized technicians and also the awareness of people who work in these types of industrial plants. In the cities of Sonora the corrosivity levels (CL) were lower than that shown in the cities of Baja California. In the cities of Sonora the levels percentage of air pollutants that exceeded the air quality standards was $50 \%$ in the year. Instead in the cities of Baja California the levels percentage was $80 \%$ in the year $[7,8]$. The reason of the differences of the indoor and outdoor deteriorated atmospheres was the awareness of the populations of each city, where the government authorities made diverse activities to reduce the air pollution. The sulfides were the major air pollutants in arid and semiarid zones and the chlorides in marine environments are the chemical agents that have a faster reaction and are constant with metal surfaces of food containers.

1.4. Climatic Factors. In all zones evaluated, the ranges of $\mathrm{RH}$ and temperature are in the levels of generation of MO. In the arid zone as Hermosillo in the Sonora State, and Mexicali in Baja California State, the higher ranges of temperature are presented, following the semiarid region as Santa Ana and 
Sonora and then the marine zone as Guaymas in the Sonora State and Tijuana in the Baja California State. In change the relative humidity was higher in Mexicali and Tijuana in the Baja California State, following Hermosillo and then Santa Ana, in the Sonora State. In these cities, the major possibility of generation of $\mathrm{MBC}$ is in winter by the condensation phenomena, originating first the uniform corrosion in the full area [3]. This generates very fast the MBC, by the accumulation of drops of water in zones of the steel cans, which are not planes (with holes and undulations). In marine environments as Tijuana in Baja California, the ranges principally of $\mathrm{RH}$ promote the MBC very fast. In the food industries of Sonora there are control systems of humidity (CSH) to maintain the adequate levels to avoid the generation of thin layers of water and originate the MBC. The CSH detect any drop of water and operate a fan to preserve the dry materials inside of industrial plants and avoid the development of $\mathrm{MO}$ [13].

1.5. Development of Microorganisms in Meat Products. The microorganisms most commonly developed in canned foods are classified according to their degree of acidity and alkalinity with $\mathrm{pH}$ ranges established. The groups of this size are low acid ( $\geq 5)$, normal acid (4.5 to 5), acid (3.7 to 4.5 ), and very acid $(\leq 3.7)$. The first two groups are presented in meat products from beef and chicken, with the aerobic spore forming, anaerobic spore, yeasts, molds, and bacteria nonsporulating average $\mathrm{pH}$ levels below 5 [14]. Under the presence of heat, the MO are developed as psychrophilic, mesophilic, thermophilic, and thermoduric, where the latter two are the most interesting from the standpoint of heat treatment. Thermophiles are capable of growing at elevated temperatures $\left(55^{\circ} \mathrm{C}\right.$ and more), whereas the thermoduric ones are able to withstand the effect of high temperatures. However, the mesophilic organisms can be thermoduric due to their spores, as the thermophilic bacteria spores can be. Some researchers consider that thermophilic organisms are classified in two groups: thermophilic forced (grown at $55^{\circ} \mathrm{C}$ but not at $37^{\circ} \mathrm{C}$ ) and thermophilic facultative (growing at $55^{\circ} \mathrm{C}$ and $37^{\circ} \mathrm{C}$ ). According to the oxygen needs the MO can be aerobic (requiring the presence of $\mathrm{O}_{2}$ ), anaerobic (developed with absence of $\mathrm{O}_{2}$ ).

1.6. MO Generates Acid Products. In most cases is easily controlled by a relatively short heat treatment at a temperature below $100^{\circ} \mathrm{C}$. Next the principal MO developed in the food industries are presented.

(a) Spore Forming Bacteria. There are microorganisms as saccharolytic anaerobic bacteria responsible for the deterioration of meat and poultry food. Within the first stand Clostridium pasteurianum and C. butyricum produce the gaseous alteration in the $\mathrm{SC}$ and do not grow at $\mathrm{pH}$ below 3.7. Another $\mathrm{MO}$ is the Bacillus which produces an acid environment inside of SC very fast, causing abnormal flavors. This $\mathrm{MO}$ is thermophilic and develops at $\mathrm{pH}$ of 4.2. B. macerans produces the deterioration of meat and poultry at $\mathrm{pH}$ of 3.2.

(b) Nonsporulating Bacteria. They are a bacterium that produces lactic acid (cocci and bacilli) and sometimes generates gas. They can be developed with low oxygen and are destroyed by heat treatment at less than $100^{\circ} \mathrm{C}$. Lactobacillus brevis, Leuconostoc mesenteroides, and Leuconostoc pleofructi forming gas.

(c) Yeast. It presents little resistance to heat, so they are not common in heat-processed canned foods, and a treatment of heat leaks occurs.

(d) Molds. Byssochlamys fulva species is the most important molds in acid canned foods. It affects canned foods very fast. It is responsible for the disintegration of the meat and poultry food as material decomposition pectinic. SC sometimes bulges due to carbon dioxide evolution. Its optimum growth temperature is $30-37^{\circ} \mathrm{C}$ and it is highly resistant to heat. Other $\mathrm{MO}$ are Byssochlamys nivea, Penicillium, Aspergillus, Rhizopus nigricans, and Rhizopus stolonifer, which deteriorate the food very quickly [15].

1.7. Effect of Food Deteriorated by MO in Human Health. The deteriorated food has a negative effect in the human health with different symptoms. The principal adverse consequences are upset stomachs, headaches, nausea, vomiting, diarrhea, and dehydration, causing the need for urgent medical attention and the possibility of developing serious diseases [16]. The air pollution is an important factor, which is considered with great care by specialists of food industry. This causes the fabrication of food products with poor quality and thus generates the diseases in the consumers and originates lawsuits affecting the economy of the industries. People who are more likely to have a negative effect on their health from contaminated food are children and the elderly. During food processing as heating or fermentation processes, MO can be generated by the air pollutants inside of food industries [17]. These chemical agents are presented from the storehouse to the final step of the manufacturing process. In the raw materials air pollutants are added to the metallic surfaces as steel used in the steel cans. Also in summer the air pollutants penetrate by air-conditioning systems and the interchange of air flow. This phenomenon occurs in the cities with arid and semiarid environment. So in winter people leave doors and windows open and allow access to air pollutants [18]. These activities are presented in marine regions. In the cities of Sonora State the indoor environments were controlled well, but in the cities of Baja California State this was not controlled. By the chemical agents mentioned above, chemical reactions are formed among the steel cans during the process and deteriorate the food. The presence of these contaminants in processed foods cannot be avoided completely [5]. However, technological processes can be adjusted or optimized to reduce them.

1.8. Electronic Devices and Equipment. The components more used to detect and control the manufacturing processes of food industries are electronic devices and equipment. They are of many types, depending on its use and the size as nano-, micro, small, medium, and big dimensions. The electronic devices are divided into two principal compositions to control electrical systems being digital (with low energy) and analog 


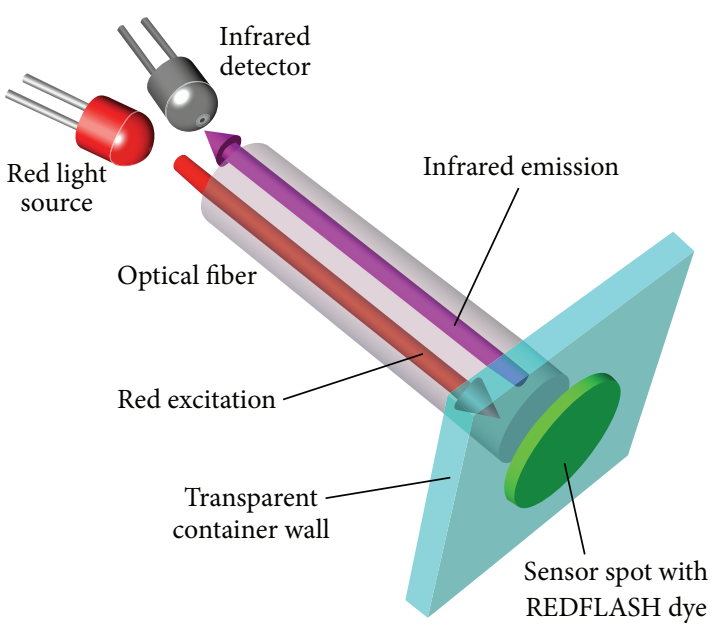

FIgURE 2: Optical sensor used to detect particles that react with the food products. (Source: optical sensors consulted in http://www .pyro-science.com/.)

(with high energy). The electronic elements used as digital are the microchips, which are very fast in their operations and are fabricated to detect micro and small particles in the control systems [3]. These components are utilized to characterize electrical, mechanical, thermal, and optical properties. To obtain the major yielding of the electronic devices it is necessary to know the specifications to be used as adequate way and in the operations required. The electronic devices and equipment obtain a lot of exact information to control the inadequate operations.

1.9. Optical Sensors Used in the Food Industries. These types of sensors are used to detect particles or MO that are not visible to the naked eye. These electronic devices generate an electrical signal that is sent to an actuator to activate a mechanism to separate the damaged products (Figure 2). The principal components of an optical sensor are the relay and the transistor that are considered as the section of interruption as a switch, to open and close the way of the electrical flow $[7,8]$. These optical sensors can detect nano-, micro, small and big particles that are added to the food products. These strange particles cause the formation of different types of $\mathrm{MO}$ and the generation of $\mathrm{MBC}$, originating the deterioration of food. This occurs principally in periods with $\mathrm{RH}$ higher than $75 \%$.

\section{Experimental}

The study was divided into three steps as mentioned below.

2.1. Climate Factors. The climate is composed of several parameters, where the relative humidity and temperature are the most important factors of the generation of $\mathrm{MBC}$. Scientists analyzing atmospheric corrosion consider to origin as the generation of an electrochemical process in the steel cans. Drastic changes in humidity and temperature at certain times of year cause the deterioration of metallic surfaces of steel cans due to the corrosivity levels [19].
2.2. Corrosion Tests. The steel cans were exposed to observe the process of generation of microbial corrosion, internal conditions of the food industry for periods of months one, three, six, and twelve in Hermosillo, Santa Ana, and Guaymas in the Sonora State, and Mexicali and Tijuana in the Baja California State. A study according to ASTM standards, correlated with the minimum outdoor average and maximum relative humidity, wetting time $(\mathrm{TH})$, and parameters temperature and concentration levels of $\mathrm{SO}_{2}$ in arid and semiarid regions and chlorides in marine environments, was made. After each exposure period, the steel samples were removed, and the weight loss was obtained, to calculate the corrosion rate $(\mathrm{CR})[20,21]$.

2.3. Microscopy and Spectroscopy Techniques. The morphology of the corrosion products was examined with an optical microscope scanning electron microscope SEM technique. This technique of examination was used to determine the morphology of the surface by EDX microscale, to determine pollutants which reacted with the inner metallic surfaces of SC. The Auger Electron Spectroscopy (AES) technique was used to determine the chemical composition in the internal spaces of SC, where the MBC was developed [22].

\section{Results and Discussion}

The generation of MBC by the atmospheric corrosion promoted the formation of $\mathrm{MO}$, and it occurred in the majority of the food industries. This analysis was to determine the kinetic process of the electrochemical phenomena presented, as the capacity to solve problems of the presence of corrosion. The economic losses decrease around 30\% and managers were concerned with this, the competitiveness being low.

3.1. Correlation of Climatic Factors with CR in SC. The RH and temperature are the factors that accelerate the corrosion rate more in steel cans used to conserve any type of food, the $\mathrm{RH}$ being the climatic factor with a major effect in the increasing of the corrosion rate. As the corrosion rate is higher in the winter, this study represents the evaluation in food industry of the cities mentioned in this period as shown in Tables 1 and 2. Table 1 indicates the correlation of CR and the climatic factors with concentration levels of sulfur dioxide $\left(\mathrm{SO}_{2}\right)$ in arid zones as Hermosillo and Mexicali, the CR being higher in Mexicali as shown in Table 1. In Mexicali the air quality standards are stringent, but in Hermosillo the companies are harder in these regulations. In Santa Ana, considered as semiarid region, the CR was lower than other cities mentioned including the marine environments. In coastal cities as Guaymas in Sonora and Tijuana in Baja California as shown in Table 2, the CR was correlated with the chloride particles that have accelerated the CR, not as the $\mathrm{SO}_{2}$, but have is a factor to deteriorate the $\mathrm{SC}$. The regulations in Guaymas are harder than Tijuana.

3.2. SEM and AES Analysis. The development of MO within the steel cans was detected by the SEM equipment at microscale of 10x. The MO formed are represented in each microphotography as white particles added to the steel of 
TABLE 1: Effect of RH, temperature, and $\mathrm{SO}_{X}$ in $\mathrm{CR}$ of SC in the cities evaluated for one month in winter in arid and semiarid zones.

\begin{tabular}{lcccc}
\hline City ranges & \multicolumn{4}{c}{ Sulfur dioxide $\left(\mathrm{SO}_{2}\right)$} \\
& $\mathrm{RH}^{\mathrm{a}}$ & $\mathrm{T}^{\mathrm{b}}$ & $\mathrm{CL}^{\mathrm{c}}$ & $\mathrm{CR}^{\mathrm{d}}$ \\
\hline $\begin{array}{l}\text { Hermosillo } \\
\quad \text { Max }\end{array}$ & 84.3 & 35.6 & 0.21 & 187.8 \\
$\quad$ Min & 45.6 & 19.9 & 0.13 & 123.4 \\
Santa Ana & & & & \\
$\quad$ Max & 78.8 & 28.3 & 0.12 & 145.7 \\
$\quad$ Min & 31.1 & 17.1 & 0.05 & 109.8 \\
Mexicali & & & & \\
Max & 84.3 & 32.7 & 0.31 & 221.4 \\
Min & 42.2 & 18.7 & 0.21 & 183.2 \\
\hline
\end{tabular}

${ }^{\mathrm{a}} \mathrm{RH}$ : relative humidity $(\%) ;{ }^{\mathrm{b}} \mathrm{T}$ : temperature $\left({ }^{\circ} \mathrm{C}\right) ;{ }^{\mathrm{c}} \mathrm{CL}$ : concentration levels of air pollution (ppm); ${ }^{\mathrm{d}} \mathrm{CR}$ : corrosion rate $\left(\mathrm{mg} / \mathrm{m}^{2}\right.$.year). Data of personal environmental monitoring.

TABLE 2: Effect of RH, temperature, and $\mathrm{SO}_{X}$ in $\mathrm{CR}$ of SC in the cities evaluated for one month in winter in marine regions (2011).

\begin{tabular}{lcccc}
\hline \multirow{2}{*}{ City ranges } & \multicolumn{4}{c}{ Chlorides $\left(\mathrm{Cl}^{-}\right)$} \\
Guaymas & $\mathrm{RH}^{\mathrm{a}}$ & $\mathrm{T}^{\mathrm{b}}$ & $\mathrm{CL}^{\mathrm{c}}$ & $\mathrm{CR}^{\mathrm{d}}$ \\
Max & 84.3 & 30.7 & 0.24 & 194.3 \\
Min & 56.3 & 18.7 & 0.15 & 133.4 \\
Tijuana & & & & \\
Max & 85.6 & 21.2 & 0.27 & 199.9 \\
Min & 25.6 & 19.3 & 0.18 & 152.1 \\
\hline
\end{tabular}

${ }^{\mathrm{a}} \mathrm{RH}$ : relative humidity $(\%) ;{ }^{\mathrm{b}} \mathrm{T}$ : temperature $\left({ }^{\circ} \mathrm{C}\right) ;{ }^{\mathrm{c}} \mathrm{CL}$ : concentration levels of air pollution (ppm); ${ }^{\mathrm{d}} \mathrm{CR}$ : corrosion rate $\left(\mathrm{mg} / \mathrm{m}^{2} \cdot\right.$ year). Data of personal environmental monitoring.

the steel cans that is shown in Figure 3 at different periods of time in an industrial plant of Mexicali. This evaluation was made in this city because in the companies of this city the MO appears faster than other cities. In Figure 3(a), the MO was formed very fast with $\mathrm{RH}$ and temperatures levels higher than $75 \%$ and $35^{\circ} \mathrm{C}$, which are very common in this city in the summer and winter periods. In these values the development of the MO and therefore, where the corrosion rate was very fast and the ranges lower of the levels mentioned of these climatic factors, the corrosion rate was minor. In other cities, the formation of MO was fast but did not reach the levels of Mexicali. Figure 3(b) shows the formation of MO in less effect; the corrosion rate being lower occurred in this zone of the steel cans. This indicates that was less concentration levels of $\mathrm{SO}_{2}$ and has less effect in the corrosion rates. The corrosion rate in Figure 3(c) shows the same level of development of the $\mathrm{MO}$, with less concentration of $\mathrm{SO}_{2}$ than the one indicated in representation of Figure 3(a). The SEM analysis was made in the winter periods meaning that at RH higher than $75 \%$, that is normal in this city in summer and winter periods, will be the possibility of the formation of MO, contaminating the food and representing danger for the human health. To determine with major specification the corrosion process the Auger and SEM techniques were used. This evaluation is explained later in detail including each microphotography
TABLE 3: Chemical composition (\%) of MO formed within SC in industrial plant located in Mexicali as in Figure 4(a) (2011).

\begin{tabular}{lccc}
\hline Chemical elements & Point A & Point B & Point C \\
\hline C & 19 & 17 & 18 \\
Fe & 15 & 21 & 17 \\
N & 18 & 23 & 21 \\
O & 25 & 20 & 24 \\
S & 23 & 19 & 20 \\
\hline
\end{tabular}

TABLE 4: Chemical composition (\%) of MO formed within SC in industrial plant located in Mexicali as in Figure 4(b) (2011).

\begin{tabular}{lccc}
\hline Chemical elements & Point A & Point B & Point C \\
\hline C & 20 & 17 & 17 \\
Fe & 19 & 21 & 18 \\
N & 21 & 23 & 20 \\
O & 17 & 20 & 24 \\
S & 23 & 19 & 21 \\
\hline
\end{tabular}

TABle 5: Chemical composition (\%) of MO formed within SC in industrial plant located in Mexicali as in Figure 4(c) (2011).

\begin{tabular}{lccc}
\hline Chemical elements & Point A & Point B & Point C \\
\hline C & 21 & 23 & 22 \\
Fe & 18 & 17 & 17 \\
N & 20 & 20 & 20 \\
O & 17 & 18 & 18 \\
S & 24 & 22 & 23 \\
\hline
\end{tabular}

analyzed with the SEM equipment. The major effect was in the meat food compared to the poultry food.

3.3. Nanoevaluation of Chemical Composition. This analysis showed the chemical composition of the MO formed within the steel cans. As shown in Figure 4, in each representation, the presence of derivate of sulfur, nitrogen, oxygen, and the iron of the material used in the steel cans, and carbon mixed with oxygen as $\mathrm{CO}_{2}$ that was detected by the high precision of the Auger equipment, indicates that MO have an acid level of $\mathrm{pH}$. The explanation of this information has after the figures. 3.2 SEM and AES analysis.

3.4. Spectroscopy Analysis. In all representations of Figure 4(a), the sulfur and oxygen had the higher concentration levels, being the principal chemical agents that generate and accelerate the corrosion rate in each point of the metallic tests evaluated. The nitrogen levels were less than the elements mentioned and the carbon was added by the exposition to the atmosphere of the metallic probes of the steel cans. This type of analysis is very important to determine the principal agents that react with metallic surface of steel cans and know the kinetic process of the corrosion phenomena in these materials. The percentage of the chemical composition is indicated in Table 3.

Tables 3, 4, and 5 indicate the percentages of chemical agents added to the metallic surfaces of SC. In Table 3 in point 


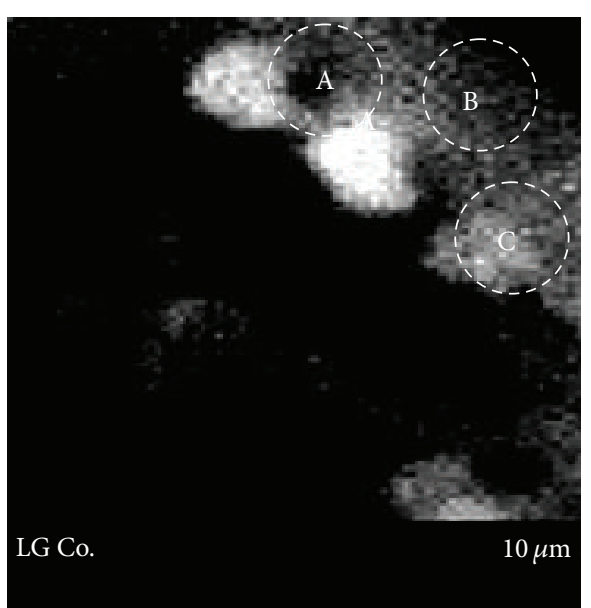

(a)

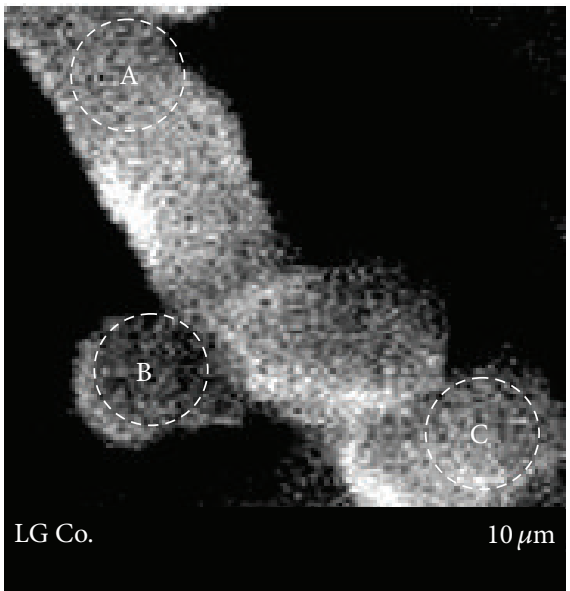

(b)

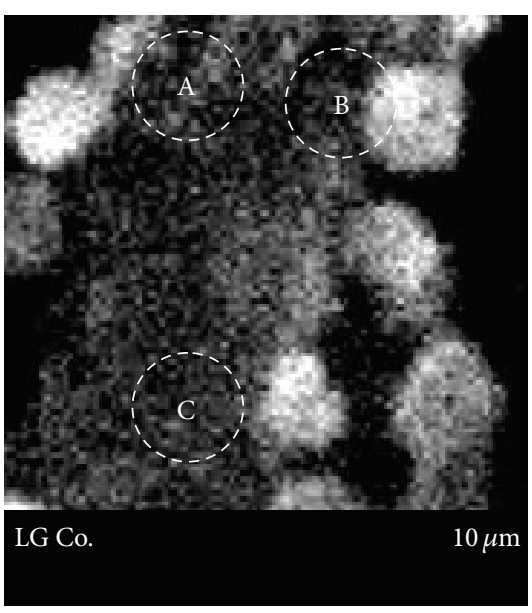

(c)

Figure 3: SEM analyses of steps of development of a spore as MO in a SC in Tijuana at (a) one day, (b) three days, and (c) six days (2011).

A, the major chemical component was the oxygen and the less quantity was the iron. In point $B$, the higher value was the nitrogen and the lower value was the carbon and in point $\mathrm{C}$, the major element was the oxygen and the minor was the iron. Then, the oxygen was a principal factor in the formation of $\mathrm{MO}$ of this zone evaluated, being in the top of the steel cans where the air of the atmosphere was higher than in the depth of the steel cans. Table 4 represents the chemical composition of the medium zone of the steel cans where the MO was formed. In point $\mathrm{A}$, the major element was the derivate of sulfur and the minor was the oxygen. In point $\mathrm{B}$, the higher value was the nitrogen and the lower quantity was the carbon. In point $\mathrm{C}$, the major one was the oxygen and the minor one was the carbon. This indicates that the combination of nitrogen, oxygen, and sulfur generates and accelerates the development of the MO. Table 5 represents the lower area of the steel cans, where in point A, the major element was the derivate of sulfur and the minor was the oxygen. In point $B$, the higher value was the carbon and the lower quantity was the iron, and in point $\mathrm{C}$, the major element was the derivate of sulfur and the lower was the iron. This means that in the depth of the steel cans, the oxygen is less than in the top of the metallic container. The $\mathrm{pH}$ measured in each zone was acid, in average of 4 , because of the formation of MO that have acidic properties.

\section{Conclusions}

The corrosion rate in the food industry located in the cities of the Baja California State was higher than the cities of the Sonora State. As mentioned above, the regulations are an important factor to avoid and decrease the corrosion rate in the SC used in the meat and poultry food industries. In the cities with the less corrosion rates, the specialized people of environmental are very hard to accept these rules. Every time the process is checked, warehouses and areas near of this to avoid the MBC. The corrosion process is very interesting in the three different zones of any steel cans: top, medium, and deep, where the $\mathrm{O}_{2}$ is an important factor as sulfur and nitrogen and arid and semiarid regions and chlorides in marine environments. The development of MO was dissimilar in each area of steel cans evaluated and the $\mathrm{pH}$ 


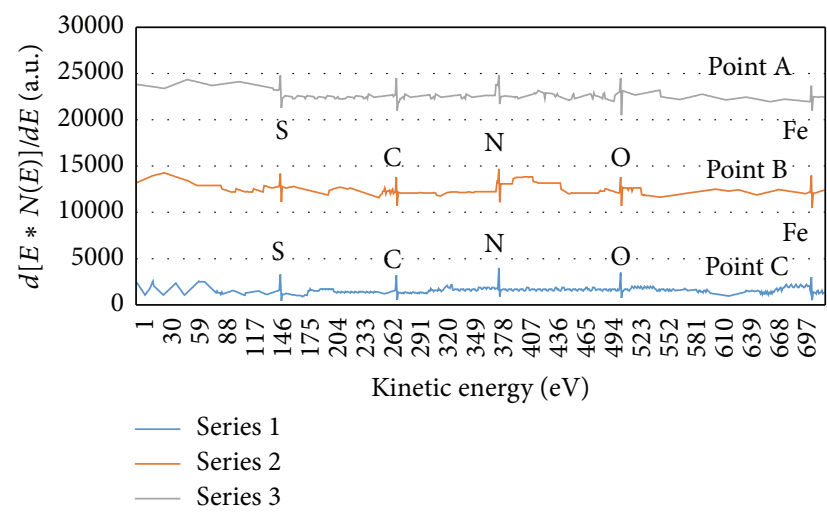

(a)

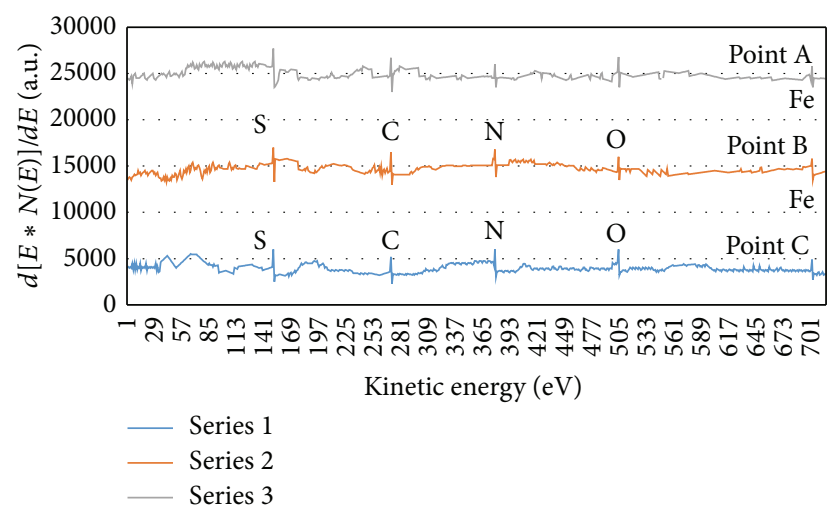

(b)

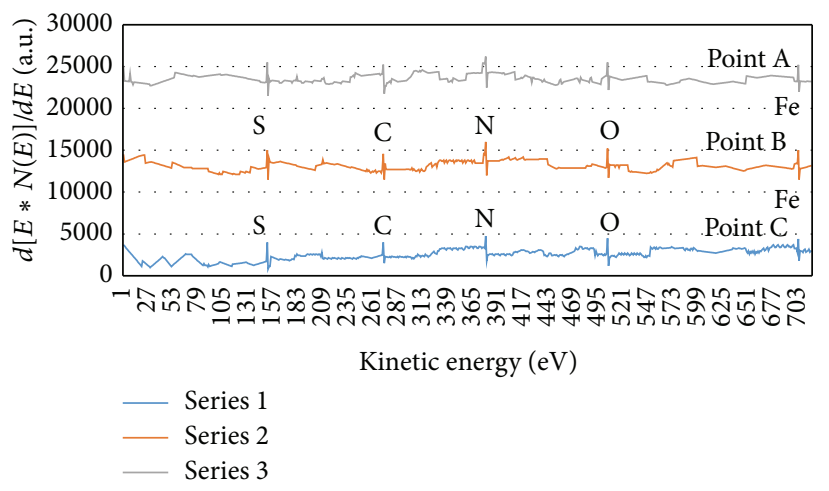

(c)

FIGURE 4: AES analyses of steps of development of a spore as MO in a SC in Tijuana at (a) one day, (b) three days, and (c) six days (2011).

was around 3 to 5 . The simulation analysis shows as influence the relative humidity and temperature in the corrosion rate, originating the relative humidity, the most adverse effect in the deterioration of steel cans. This research report was showed to two government offices of different states, where in Baja California, not was followed this study. And in Sonora was work with this regulations. For the presence of corrosion in the steel cans, companies evaluated showed on average $5 \%$ of economic losses and decrease its competitiveness, the major percentages being the company in Tijuana with 9.5\%.

\section{Conflict of Interests}

The authors declare that there is no conflict of interests regarding the publication of this paper.

\section{Acknowledgments}

Researchers give thanks to the industrial plants where are made the study and the government offices, to support to avoid the corrosion phenomena in specially the MBC.

\section{References}

[1] Bancomext, "Datos de Producción Alimenticia en México: Estadísticas del 2014,” 2014.
[2] K. Cooksey, "Effectiveness of antimicrobial food packaging materials," Food Additives \& Contaminants, vol. 22, no. 10, pp. 980-987, 2005.

[3] G. López Badilla, Caracterización de la corrosión en materiales metálicos de la industria electrónica en Mexicali, B.C. [Ph.D. thesis], 2008 (Spanish).

[4] J. R. Ibars and D. A. Moreno, "Microbiological corrosion in stainless steel of food," in Proceedings of the 22nd International Materials Research Congress (IMRC '13), Cancun, Mexico, August 2013.

[5] Canning Green Beans (CGB), Ecoprofile of Truitt Brothers Process, Institute for Environmental Research and Education, 2007.

[6] M. Avella, J. J. De Vlieger, M. E. Errico, S. Fischer, P. Vacca, and M. G. Volpe, "Biodegradable starch/clay nanocomposite films for food packaging applications," Food Chemistry, vol. 93, no. 3, pp. 467-474, 2005.

[7] G. López Badilla, S. B. Valdez, M. W. Schorr et al., "AES in corrosion of electronic devices in arid in marine environments," Anti-Corrosion Methods and Materials, vol. 6, no. 8, pp. 331-336, 2011.

[8] G. López Badilla, S. B. Valdez, and M. W. Schorr, "Spectroscopy analysis of corrosion in the electronic industry influenced by Santa Ana winds in marine environments of Mexico," in Indoor and Outdoor Air Pollution, J. Orosa, Ed., chapter 4, p. 89, InTech, Rijeka, Croatia, 2011.

[9] J. B. Lord, "The food industry in the United States," in Developing New Food Products for a Changing Market Place, A. L. Brody 
and J. Lord, Eds., pp. 1-23, CRS Press, Boca Raton, Fla, USA, 2008.

[10] M. Porter, La Ventaja Competitiva de las Naciones, Javier Vergara Editor, Mexico City, Mexico, 1991.

[11] C. Sánchez, Análisis de un modelo de competitividad aplicado a las comercializadoras de autos en Mexicali, Baja California, México [Tesis de Doctorado], 2010 (Spanish).

[12] A. E. Clark, C. G. Pantano, and L. L. Hench, "Auger spectroscopic analysis of bioglass corrosion films," Journal of the American Ceramic Society, vol. 59, no. 1-2, pp. 37-39, 1976.

[13] FAO, Corporate Repository Report; Consulted in Finkenzeller K.; RFID Handbook: Fundamentals and Applications, John Wiley \& Sons, 2nd edition, 2003.

[14] H. Brown and J. Williams, "Packaged product quality and shelf life," in Food Packaging Technology, R. Coles, D. McDowell, and M. J. Kirwan, Eds., pp. 65-94, Blackwell Publishing, Oxford, UK, 2003.

[15] J. Lange and Y. Wyser, "Recent innovations in barrier technologies for plastic packaging. A review," Packaging Technology and Science, vol. 16, no. 4, pp. 149-158, 2003.

[16] K. Nachay, "Analyzing nanotechnology," in Proceedings of the 22nd International Materials Research Congress (IMRC '13), Cancun, Mexico, August 2013.

[17] J. Weiss, P. Takhistov, and D. J. McClements, "Functional materials in food nanotechnology," Journal of Food Science, vol. 71, no. 9, pp. R107-R116, 2006.

[18] S. Ray, S. Y. Quek, A. Easteal, and X. D. Chen, "The potential use of polymer-clay nanocomposites in food packaging," International Journal of Food Engineering, vol. 2, no. 4, pp. 1556-3758, 2006.

[19] International Organization for Standardization (ISO), "Corrosion of metals and alloys, corrosivity of atmospheres, classification," ISO 9223:1992, International Organization for Standardization (ISO), Geneva, Switzerland, 1992.

[20] International Organization for Standardization (ISO), "Corrosion of metals and alloys-classification of low corrosivity of indoor atmospheres- determination and estimation of indoor corrosivity," ISO 11844-1:2006, International Organization for Standardization (ISO), Geneva, Switzerland, 2006.

[21] International Organization for Standardization (ISO), "Corrosion of metals and alloys-classification of low corrosivity of indoor atmospheres-cetermination and estimation attack in indoor atmospheres," ISO 11844-2:2005, International Organization for Standardization (ISO), Geneva, Switzerland, 2005.

[22] Wear and Erosion: Metal Corrosion, vol. 0302 of Annual Book of ASTM Standards, ASTM International, West Conshohocken, $\mathrm{Pa}, \mathrm{USA}, 2000$. 

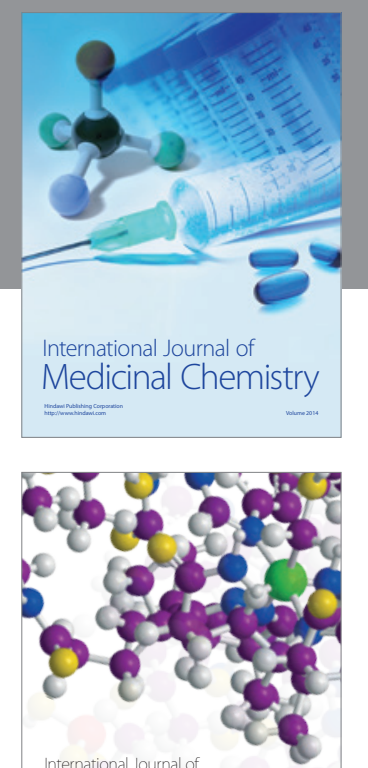

\section{Carbohydrate} Chemistry

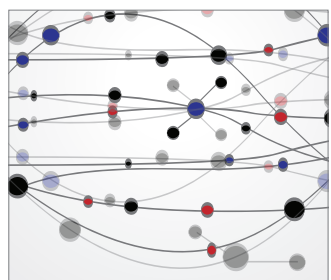

The Scientific World Journal
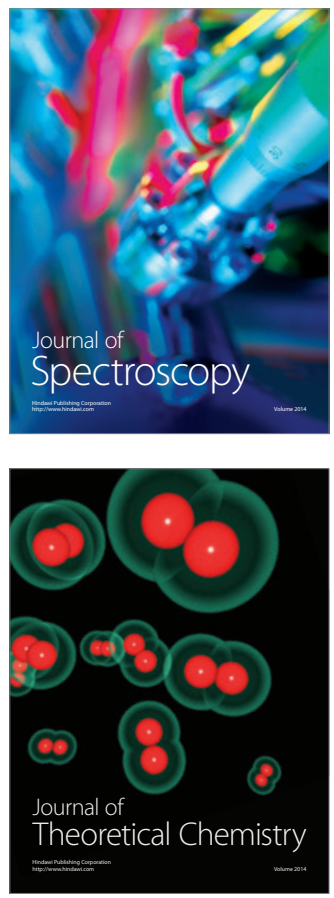
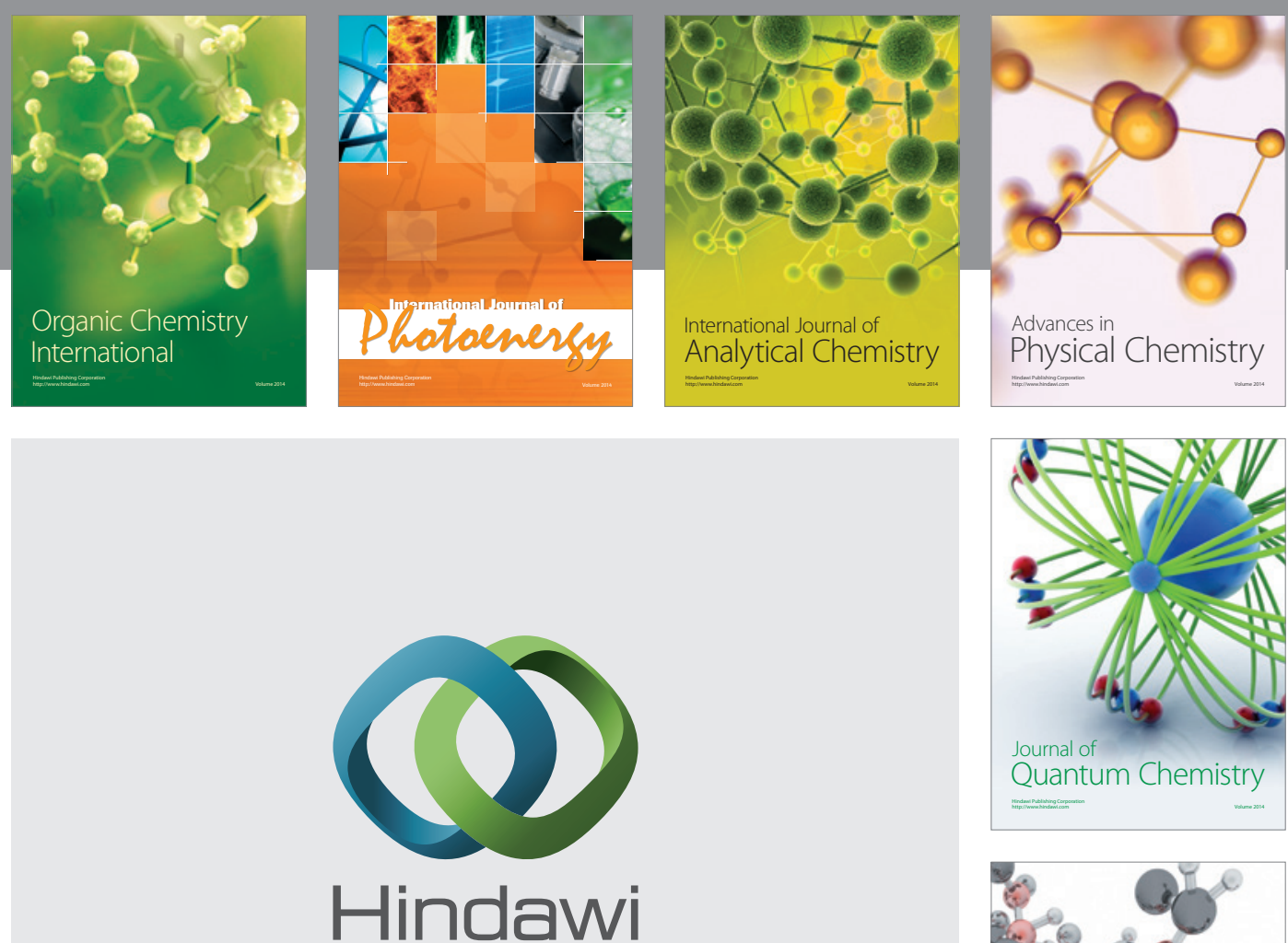

Submit your manuscripts at

http://www.hindawi.com

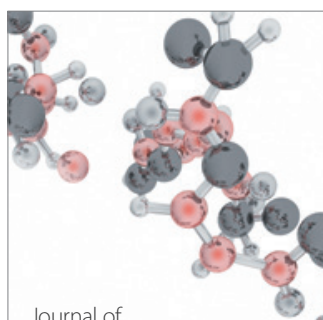

Analytical Methods

in Chemistry

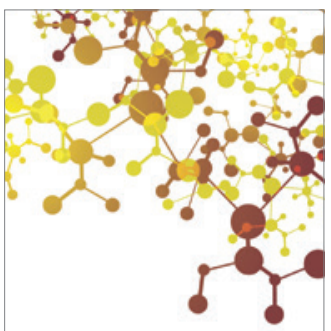

Journal of

Applied Chemistry

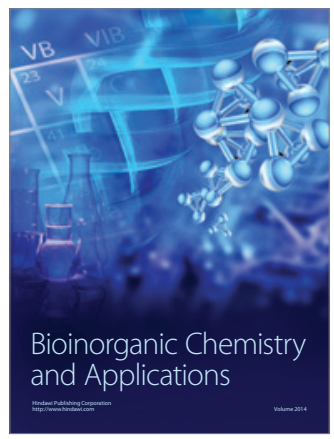

Inorganic Chemistry
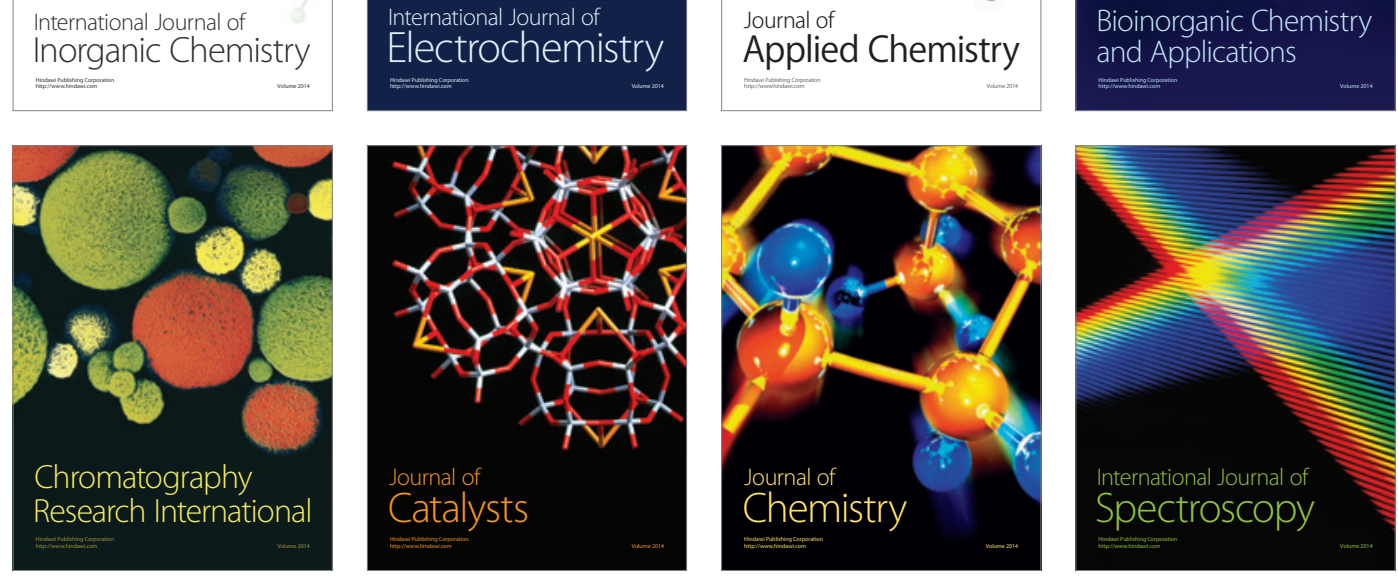